\title{
ALAT MONITORING TRANSFORMATOR MENGGUNAKAN METODE TRACKING BERBASIS ARDUINO PADA PT. PLN
}

\author{
Supardi Sigit ${ }^{1}$, Fajri Setiawan ${ }^{2}$ \\ ${ }^{1}$ Dosen STMIK Raharja Jurusan Sistem Komputer, ${ }^{2}$ Mahasiswa STMIK Raharja \\ Jurusan Sistem Komputer \\ 1,2Jl.Jendral Sudirman No.40, Modern Cikokol, Tangerang \\ e-mail: ${ }^{1}$ supardi@raharja.info, ${ }^{2}$ fajri.setiawan@raharja.info
}

\begin{abstract}
Transformator or often called trafo is one of the electrical devices that can change the level of a voltage, transformator (trafo) plays an important role in the distribution of electricity to the public. In general, electrical devices such as trafo when working can cause heat, if it is left just like that, the temperature that continues to increase can interfere with performance or can even cause the trafo to explode due to excessive heat temperature. To overcome this, the officers of PT. PLN conduct regular checks every month, therefore to lighten the work of officers, a temperature monitoring system and trafo location information is made based on google map. Information on temperature and location statistics can be directly accessed through the smartphone application that is already available
\end{abstract}

Keywords: Transformator, Trafo, Electrical, Real Time, Notification, Smartphone, arduino, esp8266.

\begin{abstract}
ABSTRAKSI
Transformator atau sering disebut juga trafo adalah salah satu alat listrik yang dapat mengubah taraf suatu tegangan, transformator (trafo) memegang peranan penting dalam pendistribusian tenaga listrik kepada masyarakat luas. Pada umumnya alat-alat listrik seperti trafo pada saat bekerja dapat menimbulkan suhu panas, jika hal tersebut dibiarkan begitu saja suhu yang terus meningkat dapat mengganggu kinerja atau bahkan dapat menimbulkan trafo tersebut meledak dikarenakan suhu panas yang berlebih. Untuk mengatasi hal tersebut maka petugas PT.PLN melakukan pengecekan secara berkala setiap bulannya, oleh karena itu untuk memperingan pekerjaan petugas maka dibuatlah sebuah sistem pemantauan suhu dan informasi lokasi trafo berbasiskan google map. Informasi mengenai statistik suhu dan lokasi dapat langsung diakses melalui aplikasi smartphone yang sudah tersedia.
\end{abstract}

Kata Kunci: Transformator, Trafo, Listrik, RealTime, Notifikasi Smartphone, arduino, esp8266. 


\section{PENDAHULUAN}

Transformator adalah komponen listrik yang mampu mengubah taraf suatu tegangan, transformator (trafo) memiliki peranan penting dalam pendistribusian tenaga listrik. Alat-alat listrik seperti trafo umumnya saat bekerja dapat menimbulkan suhu panas, jika hal tersebut dibiarkan begitu saja suhu yang terus meningkat dapat mengganggu kinerja atau bahkan dapat menimbulkan trafo tersebut meledak dikarenakan suhu panas yang berlebih suhu maksimal sebuah trafo adalah $40^{\circ} \mathrm{C}$.

Selama ini untuk memeriksa keadaan suhu sebuah trafo, petugas PLN melakukannya masih secara manual untuk melakukan pemeriksaan secara berkala setiap bulannya. Dalam hal ini penulis mempunyai gagasan untuk membuat sebuah alat monitoring suhu trafo yang berbasiskan Internet Of Things yang berjudul "alat monitoring transformator menggunakan metode tracking berbasis arduino", alat pemantau suhu trafo ini berfungsi untuk mempermudah petugas PLN melakukan monitoring suhu secara realtime

Alat pemantau suhu trafo ini juga berbasiskan google maps agar petugas dapat mengetahui titik lokasi trafo yang dapat langsung diakses melalui aplikasi android sehingga saat terjadi kerusakan yang disebabkan oleh suhu panas berlebih petugas dapat segera mengatasi trafo yang bermasalah tersebut.

\section{LANDASAN TEORI}

\section{A. Internet of things}

Ratnawati dan Silma (2017:149) . "Internet of things adalah suatu objek yang memiliki kemampuan untuk mentransfer data melalui jaringan tanpa memerlukan interaksi manusia ke komputer. Internet of things pertama kali dimunculkan oleh Kevin Ashton pada tahun 1999 di salah satu presentasinya, cofounder and executive director of the Auto-ID Center di MIT.Internet of things mengacu pada benda sebagai representasi virtual dalam struktur berbasis Internet. Internet of things memiliki potensi untuk mengubah dunia seperti yang pernah dilakukan oleh Internet, bahkan mungkin lebih baik. Penelitian pada Internet of things masih dalam perkembangan. Oleh karena itu, tidak ada definisi standar dari Internet of things. Ukuran, ruang, dan waktu.Dalam melakukan pengembangan Internet of things . Fungsi utama dari Internet of things adalah sebagai sarana yang memudahkan untuk pengawasan dan pengendalian barang fisik maka konsep Internet of things ini sangat memungkinkan untuk digunakan hampir pada seluruh kegiatan sehari-hari, mulai dari penggunaan perorangan, perkantoran, rumah sakit, pariwisata, industri, transportasi, konserverasi hewan, pertanian dan peternakan, sampai ke pemerintahan. Baik untuk alasan keamanan untuk wilayah yang tidak mungkin dimasuki manusia, maupun untuk alasan jangkauan terhadap perangkat yang akan dikendalikan tersebut".

\section{B. Prototype}

Menurut Kermite, dkk (2015:5), "Prototipe adalah salah satu metode pendekatan sistem yang sekuensial, tahap-tahapan yang dijalankan akan lebih mudah diterima oleh calon pengguna, karena pengguna juga aktif berperan dalam pengembangan sistem.

Menurut Nurajizah (2015:215) berpendapat bahwa Prototype didefinisikan sebagai satu versi dari sebuah sistem potensial yang memberikan ide bagi para 
pengembang dan calon pengguna, bagaimana sistem akan berfungsi dalam bentuk yang telah selesai.Dasar dari pemikiran ini adalah membuat prototipe secepat mungkin, bahkan dalam waktu semalam, lalu memperoleh umpan balik dari pengguna yang akan memungkinkan prototype tersebut diperbaiki kembali dengan sangat cepat.

Berdasarkan kutipan diatas maka dapat disimpulkan bahwa metode prototype adalah metode pengembangan sistem atau perancangan sistem dengan cara pendekatan atau pengenalan sistem tersebut kepada calon pengguna.

\section{Mikrokontroler}

Malik dalam Dony dan Abdul Haris (2014:2) bahwa "Mikrokontroler adalah sebagai sebuah sistem komputer yang dibangun pada sebuah keping (chip) tunggal".

Saefullah dalam Dony dan Abdul Haris (2014:2) "Mikrokontroler merupakan komponen utama atau biasa disebut juga sebagai otak yang berfungsi sebagai pengatur pergerakan motor (Motor Driver) dan pengolah data yang dihasilkan oleh komparator sebagai bentuk keluaran dari sensor"

\section{Mikrokontroller Arduino ATmega328}

Menurut Simanjuntak,dkk (2017:64) "mikrokontroler adalah sebuah sistem komputer fungsional dalam sebuah chip. Di dalamnya terkandung sebuah inti prosesor, memori (sejumlah kecil RAM, memori program, atau keduanya), dan perlengkapan input output. Dengan kata lain, mikrokontroler adalah suatu alat elektronika digital yang mempunyai masukan dan keluaran serta kendali dengan program yang bisa ditulis dan dihapus dengan cara khusus, cara keranja mikrokontroler sebenarnya membaca dan menulis data".

Menurut Djuandi dalam Ramakumbo (2014:3). Beberapa keunggulan Mikrokontroller Arduino ATmega328 yakni sebagai berikut:

a. Terdapat 130 macam instruksi yang hampir semuanya dieksekusi dalam satu siklus clock.

b. 32 x 8-bit register serba guna.

c. Kecepatan mencapai 16 MIPS dengan clock $16 \mathrm{MHz}$.

d. 32 KB Flash memory dan pada arduino memiliki bootloader yang menggunakan $2 \mathrm{~KB}$ dari flash memory sebagai bootloader.

e. Memiliki Electrically Erasable Programmable Read Only Memory (EEPROM) sebesar $1 \mathrm{~KB}$ sebagai tempat penyimpanan data semi permanent karena EEPROM tetap dapat menyimpan data meskipun catu daya dimatikan.

f. Memiliki Static Random Access Memory (SRAM) sebesar 2KB.

g. Memiliki pin I/O digital sebanyak 14 pin 6 diantaranya Pulse Width Modulation (PWM) output.

h. Master / Slave SPI Serial interface

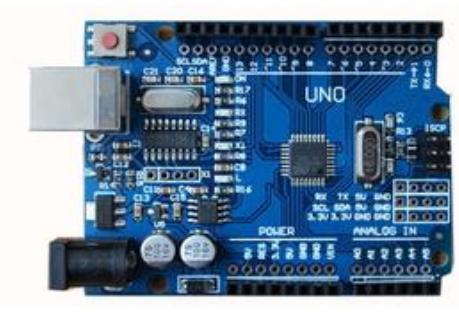

Gambar 1 Mikrokontroler ATmega328 


\section{E. Ubidots}

Menurut Kuriando, dkk (2017:2) Ubidots adalah sebuah IoT cloud atau platform internet of things yang berasal dari Boston, Amerika Serikat. Platform ini bertujuan untuk mempermudah pembuat dalam pengambilan data dari sensor dan mengubahnya menjadi Informasi. Ubidots digunakan juga untuk mengatur aksi yang dilakukan atau memberikan peringatan berdasarkan data yang didapat.

Ubidots menyediakan API untuk membantu proses pengumpulan data dan menjadikannya sebagai informasi. API adalah sebuah cara atau solusi agar benda dapat berinteraksi dengan web.

\section{PERMASALAHAN}

Mengingat akan pentingnya peranan trafo dalam pendistribusian tenaga listrik pada masyarakat luas, trafo harus dirawat dan dijaga agar kinerja sebuah trafo dapat tetap stabil dalam mendistribusikan aliran listrik. Selama ini untuk memeriksa keadaan suhu sebuah trafo, petugas PLN melakukannya masih secara manual untuk melakukan pemeriksaan secara berkala dengan cara mendatangi lokasi-lokasi trafo yang ingin dipantau kinerjanya

Maka dibuatlah sebuah sistem monitoring yang memanfaatkan teknonologi internet sebagai media pemberi informasi suhu dan informasi lokasi trafo yang mengalami masalah. Dalam perancangan sebuah sistem tentu tidak akan pernah terlepas dari beberapa permasalahan yang dihadapi. Adapun permasalahan yang dihadapi dalam perancangan sistem ini yakni sebagai berikut :

1. Bagaimana agar pihak PLN mendapatkan informasi secara realtime?

2. Bagaimana cara mengkonfigurasi lokasi pada GPS Tracker?

3. Bagaimana alat monitoring ini dapat mengirimkan data kepada petugas jika terjadinya peningkatan suhu?

\section{LITERATURE REVIEW}

1. Penelitian yang dilakukan oleh Dadang Iskandar Mahasiswa Program Studi S2 padaa tahun 2015, yang berjudul "sistem informasi gardu induk dan gardu distribusi pln" penelitian ini membahas tentang memantau keadaan Gardu Induk dan Gardu Distribusi PLN jaringan LAN sebagai jaringan internet dengan computer digunakan sebagai server yang diakses oleh computer lain.

2. Penelitian ini dilakukan oleh Muhammad Rizal Fachri, Ira Devi Sara, dan Yuwaldi Away pada tahun 2015 yang berjudul "Pemantauan Parameter Panel Surya Berbasis Arduino secara RealTime" penelitian ini membahas tentang pemantauan terhadap parameter keluaran panel surya menggunakan program aplikasi PLX-DAQ dan mikrokontroller arduino Atmega 328P sebagai data logger.

3. Penelitian ini dilakukan oleh Wahri Sunanda, Irwan Dinata pada tahun 2014 yang berjudul "Penerapan Perangkat Wireless Monitoring Energi Listrik Berbasis

Arduino dan Internet" penelitian ini membahas mengenai Pengukuran penggunaan energi listrik menggunakan sensor tegangan untuk mengukur tegangan listrik agar penggunaan listrik dapat dipantau.

4. Penelitian yang dilakukan Afrizal Fitriandi, Endah Komalasari, Herri Gusmedi pada tahun 2016 yang berjudul "Rancang Bangun Alat Monitoring Arus dan Tegangan Berbasis Mikrokontroler dengan SMS Gateway” Sistem pemantauan 
arus yang bertujuan untuk memudahkan melihat besarnya arus dan tegangan yang ada pada jaringan melalui SMS gateway. Mikrokontroler sebagai unit prosesor yang akan terintegrasi ke sensor dan komponen elektronika serta arduino uno digunakan sebagai mikrokontroler yang akan membaca inputan dari sensor yang kemudian akan dikirimkan melalui SMS gateway.

5. Penelitian yang dilakukan panji gumelar pada tahun 2018 yang berjudul "PROTOTYPE PEMANTAU BUS MENGGUNAKAN GPS TRACKING GEOLOCATION BERBASIS ADUINO UNO" Dalam perananya sebagai pemantau atau pelacak dan penentu lokasi, GPS saat ini bisa kita implementasikan kedalam konsep IoT. Dimana dapat dikembangkan lagi dengan membuat sebuah sistem halaman web maupun mobile sehingga bisa diepantau secara realtime. Dengan menggunakan module GPS, dan module GPRS/GSM, serta Arduino Uno sebagai mikrokontroler, kemudian menggunakan PHP dan JavaScript sebagai teknologi untuk merancang halaman web, maka dapat membuat sebuah GPS Tracker dengan konsep IoT

\section{HASIL DAN PEMBAHASAN}

\section{Perancangan Perangkat Keras (Hardware)}

\section{Diagram Blok Alat}

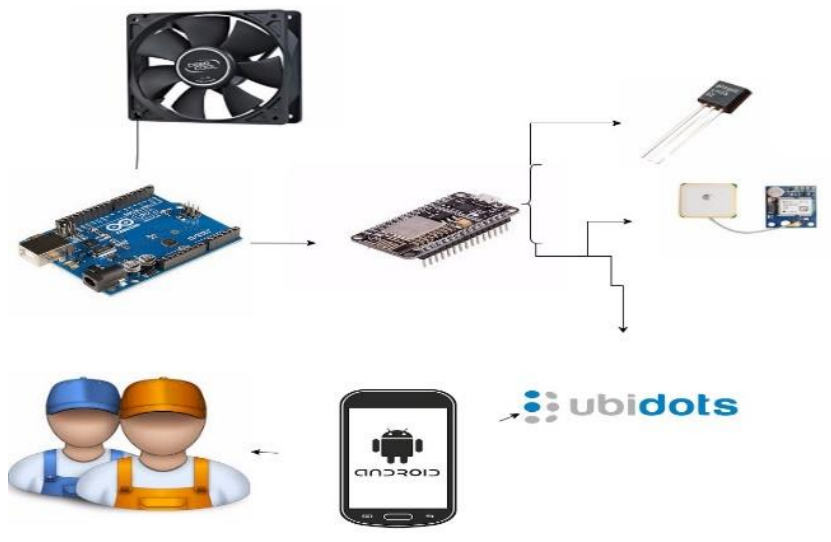

Gambar 2 Diagram Blok Alat

1) Arduino Uno berfungsi sebagai perangkat utama yang berperan sebagai inti alat-alat lainnya

2) Sensor suhu berfungsi sebagai perangkat dalam membaca suhu pada trafo.

3) LCD sebagai display/tampilan jika petugas melakukan pengecekan secara langsung pada trafo untuk mengetahui suhu trafo tersebut.

4) Kipas ini berperan sebagai pendingin jika trafo mengalami perubahan suhu yang secara drastis.

5) Wifi modul berfungsi sebagai perangkat untuk menghubungkan alat dengan webserver/jaringan.

6) Sensor GPS Tracker Ublox Neo 6 sebagai perangkat yang berperan sebagai pemberi informasi titik lokasi trafo.

\section{Cara Kerja Alat}

Untuk menggambarkan cara kerja alat pemantau trafo ini, penulis 
membuat sebuah prototype yakni sebagai berikut :

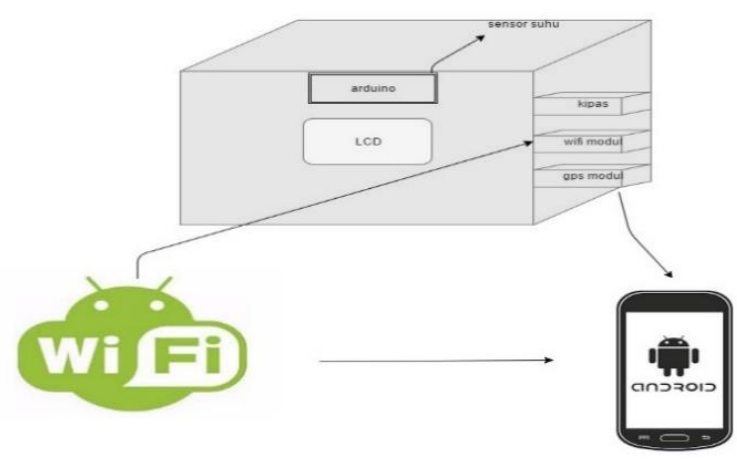

Gambar 3 Skema Prototype

Perancangan sistem pemantau trafo ini, menggunakan aplikasi smartphone android yang berbasiskan Mikrokontroller Arduino Uno dan menggunakan cloud web server yang mendukung sebagai media i/o yang hasilnya dapat ditampilkan melalui aplikasi. Dalam perancangan sistem ini dibuat menyerupai trafo yang berada pada gardu induk alat ini dibekali dengan :

1. Satu buah LCD display untuk petugas melakukan perbaikan suhu dapat dilihat melalui tampilan LCD.

2. GPS Modul untuk memberi informasi titik lokasi trafo yang sedang mengalami kerusakan.

3. Wifi Modul untuk mengirim data suhu pada web server yang nantinya dapat dilihat melalui handphone secara jarak jauh atau realtime. 


\section{Perancangan perangkat lunak (software)}

\section{Flowchart Software (Perangkat Lunak)}

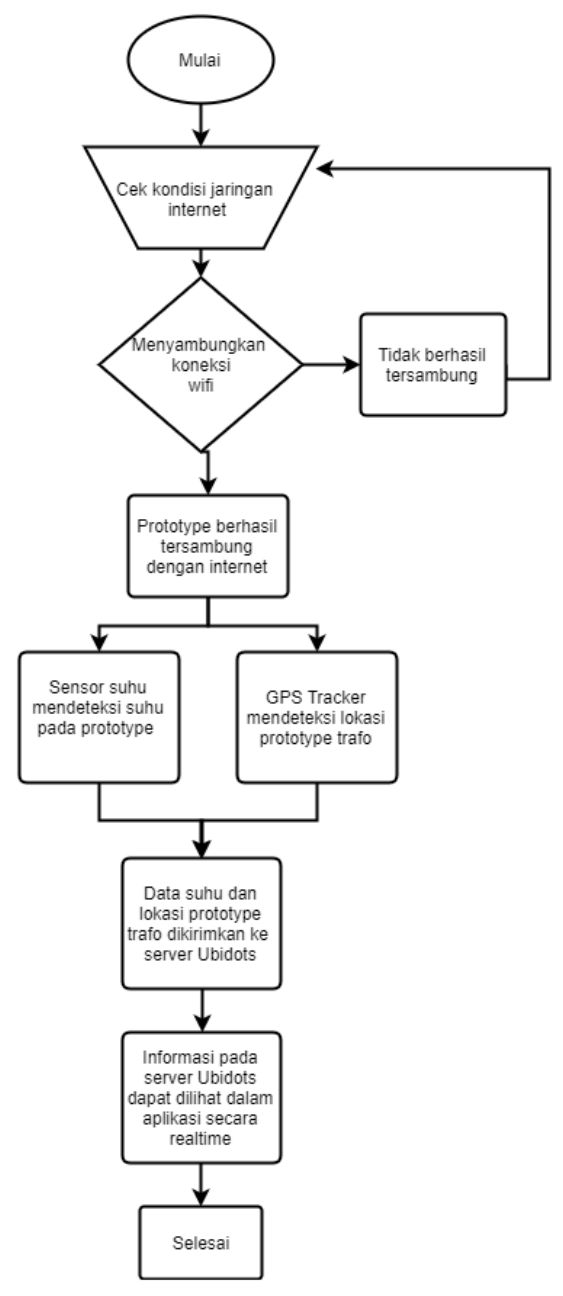

Gambar 4 flowchart software

1. Proses awal flowchart ini adalah menyambungkan wifi modul dengan hotspot, jika wifi modul gagal terhubung maka "cek kondisi jaringan".

2. Jika wifi modul pada prototype berhasil tersambung dengan hotspot, maka prototype berhasil "tersambung dengan internet".

3. Tahap selanjutnya adalah sensor suhu mendeteksi suhu pada prototype, maka data suhu akan dikirim ke server Ubidots.

4. Gps Tracker mendeteksi titik lokasi dan informasi lokasi dikirim ke server Ubidots.

\section{Rancangan Program}

Proses rancangan sistem ini untuk mendapatkan hasil antara perangkat keras yang sudah dibuat dan perangkat lunak yang sudah diprogram ke dalam mikrokontroller Atmega328 dan ESP8266, pemrograman ini dilakukan menggunakan software arduino ide dengan bahasa $\mathrm{C}++$, untuk lebih jelas mengenai pembahasan rancangan program 
maka dapat dilihat sebagai berikut:

1. Membuat sebuah program untuk melakukan push data pada server ubidots

UbidotsMaps | Arduino 1.8.5

File Edit Sketch Tools Help

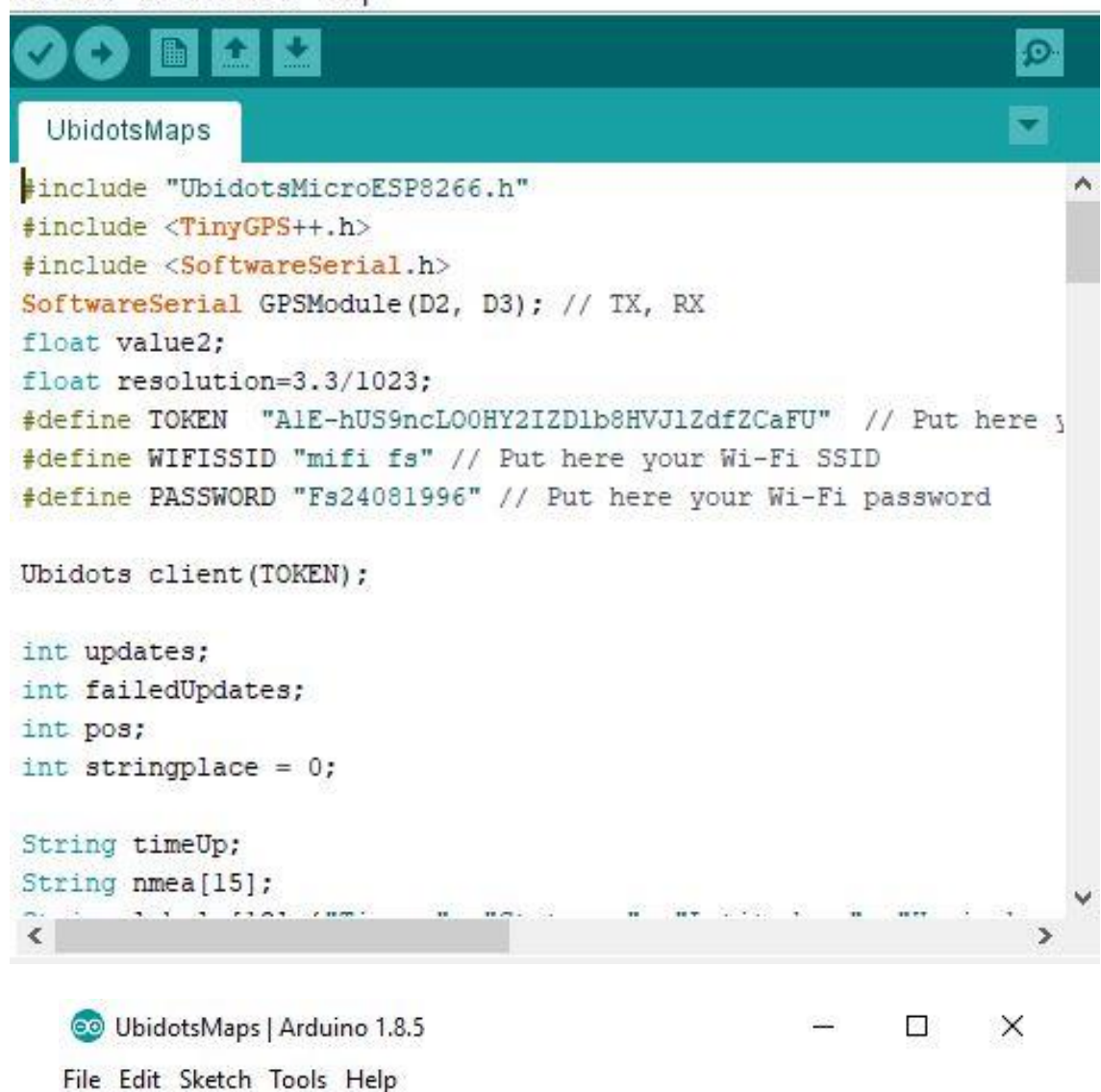

File Edit Sketch Tools Help

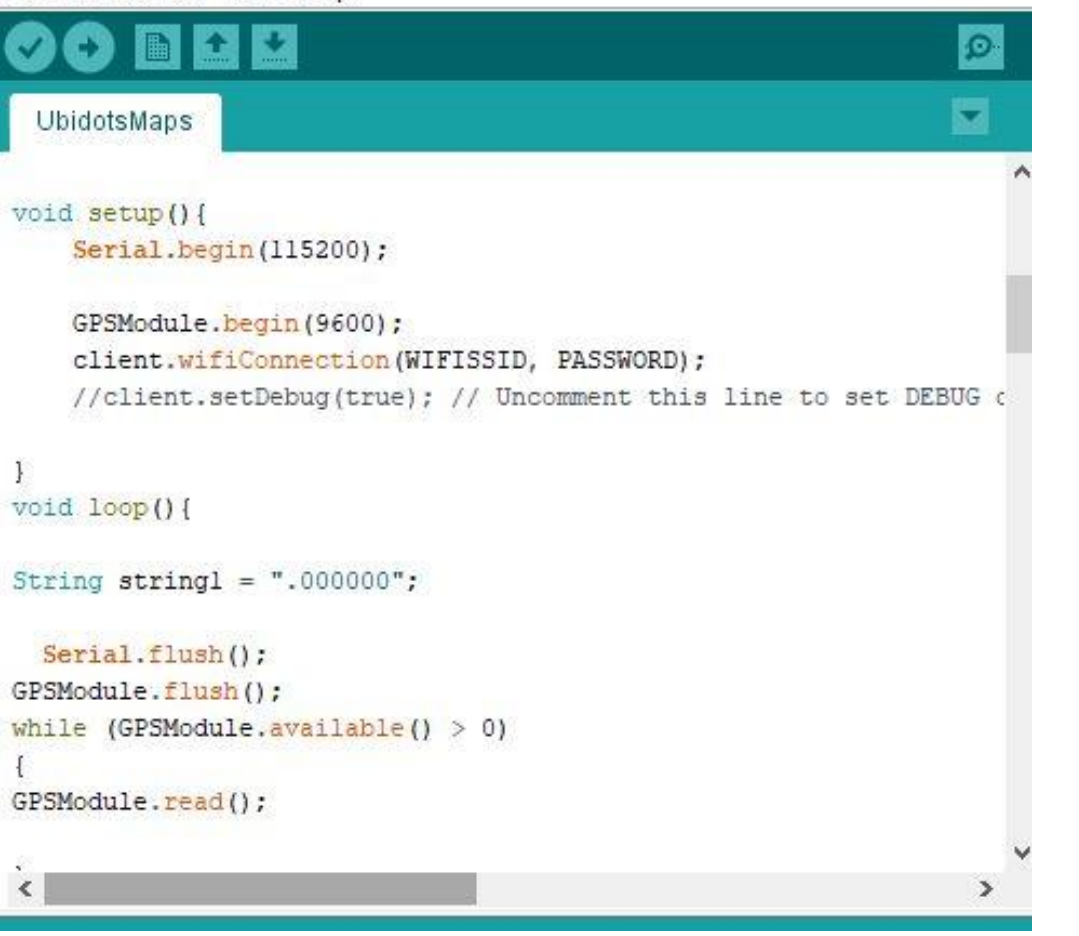

Gambar 5 Rancangan program 
2. Data terkirim, pada device yang ada pada Aplikasi Ubidots.

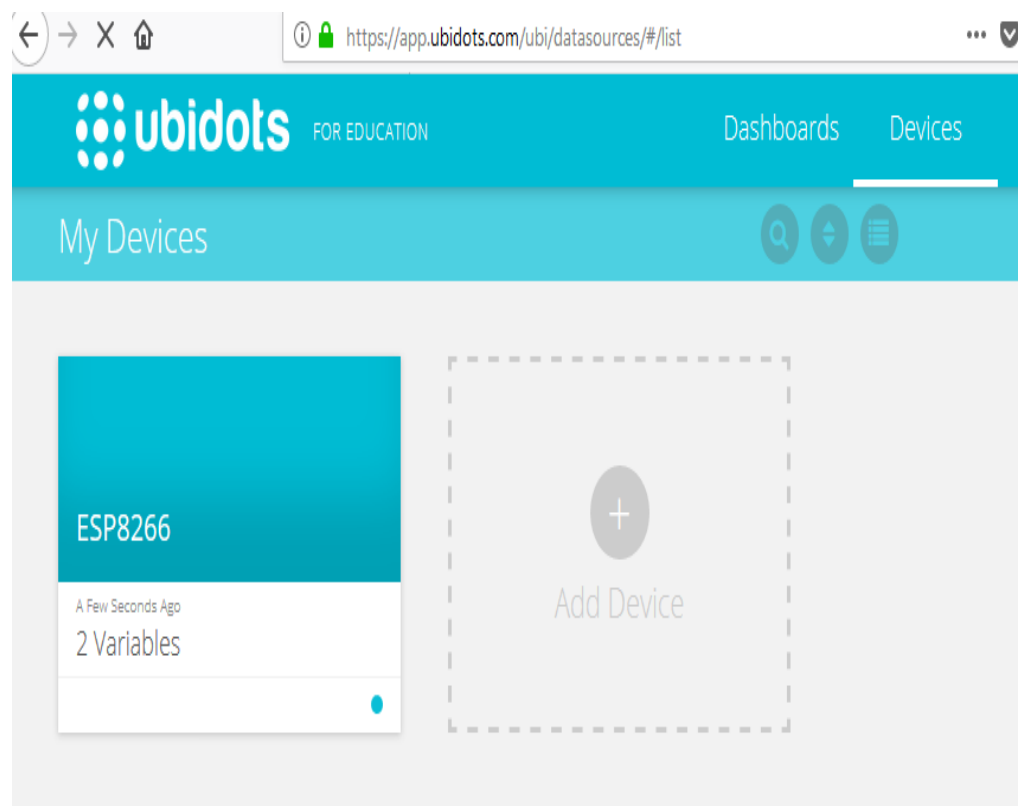

Gambar 6 data terkirim pada server

3. Tampilan prototype yang terhubung dengan google map, sebagai media informasi lokasi titik koordinat sebuah trafo

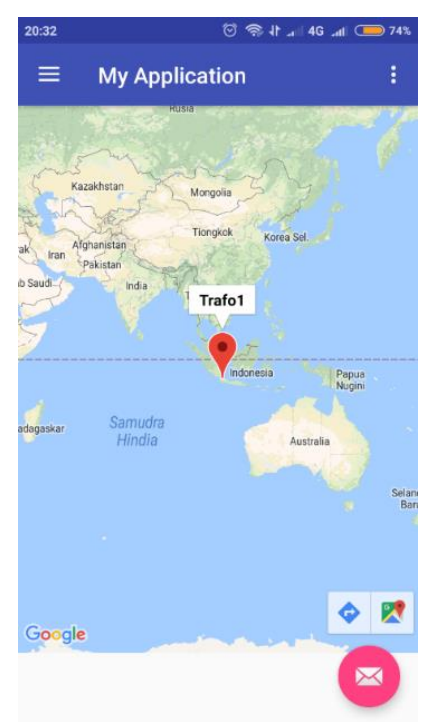

Gambar 7 titik koordinat trafo1 
4. Tampilan statistik suhu secara realtime menggunakan ubidots

\begin{tabular}{|c|c|}
\hline $15: 16$ & 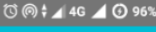 \\
\hline$\leftarrow \quad$ temperature & \\
\hline 2018-06-04 at75:16:05 & $47: 36$ \\
\hline $2018-06-04$ at $15: 16: 02$ & 47.36 \\
\hline $2018-06-04$ at $15: 16: 02$ & 47.36 \\
\hline $2018-06-04$ at $15: 16: 00$ & 47.36 \\
\hline $2018-06-04$ at $15: 15: 59$ & 47.36 \\
\hline $2018-06-04$ at $15: 15: 58$ & 47.36 \\
\hline $2018-06-04$ at $15: 15: 57$ & 46.88 \\
\hline $2018-06-04$ at $15: 12: 10$ & 47.36 \\
\hline $2018-06-04$ at $15: 12: 09$ & 47.36 \\
\hline $2018-06-04$ at $15: 12: 08$ & 47.36 \\
\hline Back & Next \\
\hline
\end{tabular}

Gambar 8 statistik suhu 


\section{DAFTAR PUSTAKA}

[1]. Ratnawati Dan Silma. 2017. Sistem Kendali Penyiram Tanaman Menggunakan Propeller Berbasis Internet Of Things. Jurnal Inspiration, vol 7.No.2.

[2]. Nurajizah, Siti. 2015. Sistem Informasi Perpustakaan Berbasis Web Dengan Metode Prototype: Studi Kasus Sekolah Islam Gema Nurani Bekasi. Seminar Nasional Inovasi Dan Tren (Snit).

[3].Kermite, Reynaldi Yosfino , Agus Winarno, Asih Rohmani. 2017. Perancangan Sistem Administrasi Sekolah Dengan Sms Gateway Berbasis Web Menggunakan Gammu Pada Smk Lpi Semarang. Joins, vol 2.No.1.

[4]. Saputra, Dony, Abdul Haris Masud. 2014. Akses Kontrol Ruangan Menggunakan Sensor Sidik Jari Berbasis Mikrokontroler Atmega328p. Seminar Nasional Teknologi Informasi Dan Komunikasi.

[5].Simanjuntak, Tri B. O , Glanny M. Ch. Mangindaan Dan Marthinus Pakiding. 2017. Rancang Bangun Sistem Kontrol Otomatis Dan Pengamatan Kondisi Baterai Pada Sistem Pembangkit Listrik Berbasis Microcontroller. E-Journal Teknik Elektro Dan Komputer, vol 6.No.2.

[6].Kuriando, Denny , Agustinus Noertjahyana , Resmana Lim. 2017. Pendeteksi Volume Air Pada Galon Berbasis Internet Of Things Dengan Menggunakan Arduino Dan Android. Jurnal Infra. 